Revista Iberoamericana, Vol. LXXVII, Núms. 236-237, Julio-Diciembre 2011, 717-730

\title{
MUJERES AL MANDO DE LA IMPRENTA: LA EDUCACIÓN CIENTÍFICA DE LA MUJER EN LA PRENSA FEMENINA ARGENTINA DEL SIGLO XIX
}

\author{
POR \\ VANESSA LANDRUS \\ Eastern Illinois University
}

\begin{abstract}
¿por qué pues, se niega el cultivo, á una mitad de los séres de la tierra? ¿Cómo querer desconocer que estamos dotadas de las mismas facultades ligadas á los mismos intereses, y en la misma posibilidad de ilustrar, y de ser ilustradas?....La Patria precisa que se hagan universal el conocimiento de las ciencias en ambos secsos, porque asi puede esperar, que la nueva generación de ciudadanos útiles y capaces de sostituir, á los que hoy presiden los altos destinos de la República.
\end{abstract}

Rosa Guerra, La Camelia (énfasis mío) ${ }^{1}$

El epígrafe anterior ilustra la tesis de la escritora Rosa Guerra, editora del periódico femenino La Camelia (1852), sobre el rol crucial de la educación científica de la mujer en el proceso de formación nacional decimonónico. ${ }^{2}$ La educación como un sistema de legitimación social y cultural, junto a la ciencia entendida en la época como el

1 Los pasajes extraídos de los periódicos y revistas literarias analizadas a lo largo de este ensayo conservan la ortografía, la gramática y los signos de puntuación originales.

2 El periódico literario La Camelia comienza a publicarse en Buenos Aires el 11 de Abril de 1852. Además de los ensayos editoriales redactados por la escritora Rosa Guerra, La Camelia contó con la participación de varias colaboradoras quienes en su mayoría contribuían a la redacción del periódico por medio de correspondencias. Su slogan, presente desde el primer número del periódico, es: "Libertad! No licencia; igualdad entre ambos secsos”, y marca el surgimiento de una nueva era en la prensa argentina en la cual la mujer se inserta en el diálogo público en "pleno goce de su derechos”. Este periódico presentó un programa sin precedentes debido a su originalidad temática y a su agudo enfoque progresista en pos de "la reivindicación del sexo femenino" (Auza 163). La falta de apoyo de sus congéneres y las duras críticas y amenazas recibidas por parte del círculo periodístico masculino ante la anomalía de su directorio y la discusión de temas que traspasaban los asuntos netamente domésticos causa la desaparición del periódico. Después de sólo catorce números, La Camelia publica su último fascículo el 11 de mayo de 1852. 
único "conocimiento cierto" de las cosas, se presenta en los artículos periodísticos de Guerra como un canal productivo por el cual se pretende absorber la alteridad femenina (Diccionario de autoridades 345). La educación como agente generador de prácticas culturales conforma en La Camelia una plataforma por medio de la cual se podía asegurar el bienestar y el orden nacional. ${ }^{3}$ La ciencia, en la visión de Rosa Guerra, constituía la única avenida válida para llegar a obtener un conocimiento certero, preciso y práctico de las cosas. La editora de La Camelia, como muchas otras periodistas que le siguieron, se dedicaba a la doble tarea de levantar conciencia sobre las injusticias que padecían las mujeres en su época y de formular propuestas concretas que apuntaran a la integración femenina y a la regeneración de la sociedad en el período de construcción nacional. Los periódicos y revistas literarias femeninas se convirtieron en un espacio orgánico singular que posibilitó la inserción de la mujer a nivel discursivo en los debates nacionalistas.

El presente artículo se enfoca en el surgimiento de las discusiones en torno a la educación científica de la mujer en la prensa femenina argentina. Se examina la promoción de la formación científica en la mujer como un mecanismo que pretende alcanzar el reconocimiento y la valorización pública de la participación femenina en el proceso de consolidación nacional. Finalmente, se explora el aporte del discurso periodístico femenino en la articulación de los proyectos que sirvieron de base para la construcción y solidificación de la nación argentina.

La contribución de la prensa femenina hacia el mejoramiento de la condición social, cultural y educativa de la mujer comienza con la fundación del primer periódico femenino La Aljaba (1830), bisemanario redactado y editado enteramente por la escritora Petrona Rosende de Sierra. ${ }^{4}$ Este periódico dedicado exclusivamente "al bello sêxo Argentino” constituyó una anomalía dentro del formato genérico de la prensa bonaerense decimonónica ya que prescindió de colaboración masculina (16 nov. 1830: 1). ${ }^{5} \mathrm{La}$

3 Pierre Bourdieu sostiene que las prácticas y necesidades culturales son un producto del nivel de educación formal del individuo (1). El ordenamiento jerárquico de una sociedad se construye por medio de una imposición de "títulos" los cuales son generados por el sistema educativo (23).

4 Cabe señalar que a partir de 1820 surgieron varios periódicos redactados por el Padre Francisco Paula de Castañeta, los cuales llevan títulos femeninos como Doña María Retazo o La Matrona Comentadora de los Cuatro Periodistas (De Marco 105). En la época en que comenzó a publicarse La Aljaba, también circulaban algunos periódicos editados por Luis Pérez que tenían títulos femeninos. Me refiero a $L a$ Gaucha (1831), La Negrita (1833), y La Tricucha (1833), los cuales eran de orientación netamente federal (Verdevoye 367). Dentro de este grupo de periódicos también se destaca La Argentina (18301831), el cual simulaba estar escrito por una mujer pero en realidad estaba enteramente redactado por el escritor Manuel Irigoyen.

5 Petrona Rosende de Serna es considerada la primera periodista argentina. A pesar de haber nacido en Montevideo, Uruguay el 18 de octubre de 1787, esta escritora residió en Buenos Aires la mayor parte de su vida en donde, además de fundar su bisemanario La Aljaba, colaboró en el periódico La Argentina (1830-1831) y Parnaso Oriental (1835-1837). Detalles sobre la vida y obra de Rosende de Sierra se pueden encontrar en Lily Sosa de Newton (553-54).

$\begin{array}{lllll}\text { ISSN 0034-9631 (Impreso) } & \text { Revista Iberoamericana, Vol. LXXVII, Núms. 236-237, Julio-Diciembre 2011, } & \text { 717-730 } \\ \text { ISSN 2154-4794 (Electrónico) }\end{array}$ 
separación de las ataduras y relaciones de poder ligadas a los agentes masculinos que hasta el momento dominaban el diálogo público permite la redacción de un medio de comunicación dedicado a la defensa y promoción de los intereses femeninos. El género ensayístico, debido a su hibridez narrativa y falta de sistematización, le proporcionó la oportunidad de cuestionar y presentar una visión crítica ante las políticas de sociabilidad vigentes en la época. Rosende de Sierra se vale de la maleabilidad del ensayo para incorporar diversas ideas y propuestas sin dependencia de un formato previamente delimitado ya que, como sostiene Doris Meyer, el mismo podía tomar la forma de una carta, una confesión, una conferencia, un diario de viaje, o un artículo científico o sociológico (5). En los ensayos editoriales de La Aljaba, como en los demás periódicos y revistas femeninas publicados posteriormente, se construye una narrativa abierta, dinámica y a la vez altamente "reflexiva" que facilitó el tratamiento profundo de temas no comúnmente abordados en la época, especialmente en la prensa argentina (Good 6). Como medio de expresión, el ensayo fuerza al lector a intelectualizarse adoptando una postura frente a las disyuntivas planteadas en la narrativa (Adorno 152). El contenido de la ensayística emitida en la prensa femenina deviene de un proceso de interpretación que genera lo que Georg Lukács denomina un "juicio de valor” sobre el asunto tratado (18). Las periodistas aportan continuamente una posición la cual no se entiende como un "veredicto", sino como un diálogo que conduce progresivamente a persuadir al lector/a a aceptar sus puntos de vista e identificarse con la ideología de cierto periódico (Lukács 18). Debido a su faceta crítica, el género ensayístico constituyó el vehículo más adecuado para la creación de un discurso revolucionario ya que resiste las reminiscencias prescriptivas y socava la ilusión de un mundo básicamente lógico y simple que se encuentra en perfecta armonía con el status quo (Adorno 163). El ensayo siempre revela un grado de escepticismo, de inconformidad convirtiéndolo en una herramienta esencial para la articulación de una narrativa alternativa.

Como se observa en el epígrafe de este trabajo, la ensayística permitió la incorporación de preguntas dirigidas a los lectores destinadas a cuestionar las nociones de diferenciación sexual que impedían el contacto de la mujer con el "estudio de materias importantes y sólidas” (La Aljaba 31 dic. 1830: 3). En esta temprana etapa del periodismo femenino se articula una labor correctiva que tiene por objetivo la redefinición del concepto de feminidad decimonónico. Se resalta la influencia de teorías filosóficas, históricas y religiosas que habían instituido en el pensamiento colectivo la condición de inferioridad femenina como contrapartida al paradigma masculino de razón y moral. De esta manera, se observa un marcado esfuerzo por identificar a la mujer como un sujeto pensante y educable. En su fascículo del 26 de noviembre de 1830, Rosende de Sierra arguye que la mujer se encontraba dotada de "disposiciones naturales" que asegurarían el éxito de su educación si se le otorgara los medios necesarios (1). Ciertos intelectuales de principios de siglo llegaron a compartir la ideología planteada previamente por Rosende

\footnotetext{
\begin{tabular}{l} 
Revista Iberoamericana, Vol. LXXVII, Núms. 236-237, Julio-Diciembre 2011, $717-730$ \\
\hline ISSN 0034-9631 (Impreso)
\end{tabular}
} 
de Sierra en cuanto a la falsa supremacía masculina y a la inminente urgencia de educar a la mujer argentina. Como editor del periódico La Moda (1838), Rafael Corbalán reconoce la necesidad de emprender una reforma de la educación femenina para que la mujer pudiera fortalecer su vínculo familiar y elevarse como el "angel protector" del hogar doméstico (13 enero 1830: 1-2). Sin embargo, no se hace alusión al aporte público de la mujer en el proceso de reorganización nacional. La influencia de la educación femenina se concibe únicamente en términos privados, como un antídoto contra las “desatendidas” ocupaciones domésticas (24 marzo 1830: 6). Es específicamente en los periódicos literarios femeninos en donde la educación de la mujer constituye la "base fundamental sobre la cual debe sostenerse el edificio social” (La Aljaba 10 dic. 1830: 1). El condicionamiento de la población se ve fuertemente influenciado por la formación educativa femenina. Las periodistas argentinas entienden a la educación de la mujer como un instrumento de orden social, disciplina y progreso nacional.

Ahora bien, las editoras y colaboradoras de los periódicos y revistas femeninas señalan las notables diferencias entre el sistema de educación femenino vigente en la época y sus proyectos de enseñanza cimentados en conocimientos científicos. Rosa Guerra es una de las editoras que subraya las falencias del aprendizaje femenino decimonónico basado, en sus propias palabras, en "el aprendizaje del piano, del dibujo y de otras fusilerías” (6 mayo 1852: 1). En su periódico, Guerra describe la enseñanza femenina de la época como “efímera” (2 mayo 1852: 1) “monótona” y “mezquina” (27 abril 1852: 1). Sus artículos editoriales denuncian el número restringido de lecturas disponibles para las mujeres de los sectores tanto urbanos como periféricos. Asimismo, se resalta la superficialidad e impracticidad de los conocimientos inculcados en las niñas como así también la falta de reflexión y deliberación en el proceso de formación educativa. Ante esta situación, las periodistas articulan proyectos educativos de carácter universal y científico que apuntan a revertir el estado de estancamiento intelectual en el que se encontraban las jóvenes de la época.

El primer proyecto científico propuesto por la prensa femenina se encuentra en la sección editorial de La Camelia, en donde Rosa Guerra remarca la necesidad de utilizar los colegios de mujeres ya instituidos, como el Colegio de Huérfanas, para implantar clases de filosofía, historia, ciencias exactas, derecho civil y medicina entre otros cursos accesorios (4 mayo 1852 1). ${ }^{6}$ La preocupación por introducir las ciencias dentro de los planes de enseñanza argentinos se continúa en la cultura impresa femenina a lo largo del siglo diecinueve. En la revista La Ondina del Plata, la escritora cordobesa María Eugenia Echenique expande el espectro de las materias científicas ya propuesto en los periódicos de mediados de siglo al introducir el pedido de clases públicas de idiomas,

6 En la época, por ciencias exactas se entendía a la química, geometría, cálculo, física experimental y astronomía (Babini 24).

$\begin{array}{lllll}\text { ISSN 0034-9631 (Impreso) } & \text { ISSN 2154-4794 (Electrónico) }\end{array}$ 
bellas artes y contabilidad. ${ }^{7}$ El conocimiento científico, hasta ese entonces reservado exclusivamente para los hombres, se considera un patrimonio común por lo que su implementación en los planes de educación femenina se ratifica como un derecho propio de la mujer y una necesidad apremiante para el futuro de la sociedad argentina.

La prensa femenina considera a la ciencia como un agente transformador y progresista. Literatas como Rosa Guerra y María Eugenia Echenique comienzan a resaltar el impacto altamente positivo de la formación científica de las madres en las futuras generaciones. Estas periodistas, lejos de cuestionar el rol maternal femenino, lo utilizan como argumento para demandar la inclusión de las ciencias en la formación educativa de las mujeres. Guerra arguye que por medio de las ciencias las madres podrían estar capacitadas para trasmitir en sus hijos un tipo de educación certera, completa y utilitaria que inclinara a los mismos hacia la causa de la regeneración nacional (27 abril 1852: 1). Su ensayística afirma que con el auxilio de las ciencias la madre podría alcanzar y preservar el bienestar social, moral, político y económico del país. Para Echenique, "la mujer científica" no sólo llegaba a comprender claramente su labor como madre, sino que su accionar ubicaba a sus hijos por la senda de la civilización. La madre que recorría el "Observatorio Astronómico con su hijo de la mano" inculcaba en éste conocimientos científicos que engrandecerían su porvenir y contribuiría al desarrollo de la patria (La Ondina del Plata 13 agosto 1876: 3). El legado científico maternal se percibe en los ensayos de Rosa Guerra y María Eugenia Echenique como uno de los pilares en donde reposaba la unidad, el orden y el desarrollo nacional. Al incorporar las ciencias en los proyectos de educación femenina, estas periodistas convierten a la maternidad en un elemento altamente productivo y decisivo en el forjamiento de la emergente nación argentina.

En la revista La Ondina del Plata, la escritora Raimunda Torres y Quiroga continúa la labor emprendida por Petrona Rosende de Sierra, Rosa Guerra y María Eugenia Echenique al enfatizar la decisiva influencia de la educación femenina en la formación de la sociedad argentina. En su artículo del 27 de febrero de 1876, esta colaboradora afirma que la "salvación" del pueblo dependía de la educación de la mujer (1). María Eugenia Echenique, por su parte, afirma que para poder "enseñar" era preciso "saber" (La Ondina del Plata 13 agosto 1876: 3). La mujer, como madre, debía "inspirar [en

\footnotetext{
7 La revista semanal La Ondina del Plata pertenece al grupo escaso de publicaciones periodísticas femeninas de larga duración. Su edición estaba dirigida por un joven estudiante, Luis Telmo Pintos, y abarcó un período irrumpido de tres años, comenzando sus publicaciones en Buenos Aires el 7 de febrero de 1875. La revista tenía un carácter global ya que incluía artículos de colaboradoras no únicamente argentinas, sino también europeas y de otras partes de Latinoamérica y Estados Unidos. Las ideas que se importan de la prensa de otros países contribuye a ese carácter global especialmente si entendemos la globalidad como "el movimiento de ideas" a través de límites geográficos y temporales que afecta no únicamente los círculos económicos, sino también culturales y políticos (Nussbaum 2).
}

$\begin{array}{lllll}\text { ISSN 2154-4794 (Electrónico) } & \text { Revista Iberoamericana, Vol. LXXVII, Núms. 236-237, Julio-Diciembre 2011, 717-730 }\end{array}$ 
sus hijos] las grandes acciones y los nobles sentimientos”, función que demandaba su incursión en las ciencias (La Ondina del Plata 13 agosto 1876: 3). Estas periodistas enfatizan que la mujer argentina, al estar despojada de la educación científica, manifestaba una tendencia egocéntrica la cual se encontraba en disidencia con sus roles de madre y esposa. La ignorancia femenina daba origen al indiferentismo familiar lo que constituía un motivo de preocupación explayado sin excepción en la prensa femenina decimonónica. Según María Eugenia Echenique, la mujer sin capacitación científica “ignora todas las cosas: no es capaz de consolar a su esposo ni de ayudarlo, no es capaz de tributarle una caricia porque ocupada de sí misma se hace exigente y despótica, se hace orgullosa y no sabe hacer la felicidad del hogar. Para ella no hay deberes que llenar sino caprichos que satisfacer" (La Ondina del Plata 13 agosto 1876: 2). Se identifica la falta del conocimiento científico en la mujer como la causante del desorden familiar. La carencia de los estudios sólidos como las ciencias exactas, y particularmente para Echenique las ciencias económicas fomentaba la absorción de las mujeres en las trivialidades de la época, perjudicando el destino material y moral de la familia y de la nación argentina. Como colaboradora de la revista La Ondina del Plata, María Eugenia Echenique se dedica especialmente a recoger las imágenes de diversas mujeres de las capitales y del interior del país con el objetivo de demostrar en sus artículos las graves consecuencias de la falta de educación científica en la mujer argentina. En el número cuarenta y uno de La Ondina del Plata, se lee:

\begin{abstract}
Visitando los suburbios de las ciudades y las campañas encuentro la corrupcion en la mujer ignorante; en que no tiene recursos para trabajar, en la que carece de medios de ganar su subsistencia á la altura de sus aspiraciones; en aquello que se deja llevar de solo los sentimientos naturales sin haberlos modificado por medio del conocimiento del corazon humano y de sus deberes; en ella encuentro el dolor, la desgracia, el llanto desesperado, la miseria absoluta, no en aquella otra que está con el libro en la mano, que sale á dar sus lecciones de física ó va á curar, como facultativa, á los enfermos ejerciendo en ellos los sentimientos generosos propios de su sexo; que se presenta en un tribunal á defender los derechos de la que llora en un rincón del pueblo, no hallo esa desgracia. (483)
\end{abstract}

La prohibición de las ciencias en la educación femenina tenía por resultado la inmersión de las mujeres, tanto porteñas como provincianas, en el infortunio y la desesperación derivada de un plan de enseñanza arcaico y obsoleto que negaba sus necesidades económicas e intelectuales. Las propuestas educativas de la prensa femenina apuntan a erradicar la ignorancia en la mujer por medio del manejo de conocimientos científicos con el propósito de ampliar sus posibilidades laborales y fortalecer su capacidad para defender sus derechos como ciudadana. El manejo de las ciencias como la física, la medicina y la abogacía se visualiza en la cultura periodística femenina como una barrera protectora contra las injusticias sociales y económicas que comúnmente recaían

Revista Iberoamericana, Vol. LXXVII, Núms. 236-237, Julio-Diciembre 2011, 717-730 ISSN 0034-9631 (Impreso)
ISSN 2154-4794 (Electrónico) 
en la mujer. El discurso testimonial de Echenique apunta a resaltar los beneficios de la capacitación científica en las jóvenes y su importancia en la articulación de los proyectos que pretendían cambiar la dinámica social decimonónica.

Los conocimientos científicos se presentan en la prensa femenina como un eje integrador y protector de la familia argentina. Las ciencias exactas y especialmente la contabilidad conformaban uno de los estudios más aconsejables para la mujer por ser de gran beneficio en el ambiente privado. María Eugenia Echenique es una de las periodistas que enfatiza el aporte que conllevaría este tipo de aprendizaje científico al entenderlo como una avenida educativa que consolidaba la unión familiar y favorecía su desarrollo económico. En la edición número cuarenta y seis de La Ondina del Plata, Echenique elabora detalladamente en la labor contable que la hija, la hermana o la madre podría desempeñar dentro del mismo hogar para defender "los intereses de la casa", evitar el contrato de "un forastero" y el posible peligro de "sufrir un quebranto" (545). Las mujeres, al estar capacitadas científicamente, podían fortalecer la unión familiar por medio de un nuevo ordenamiento laboral de grandes remuneraciones a nivel moral y económico. La prensa femenina intenta dilucidar las fronteras que dividían el accionar femenino del masculino al abogar por un sistema de educación científico universal. Como bien señala Mariselle Meléndez, el término de frontera en referencia al plano de género sexual alude a los "espacios de diferencia" que se perciben como "receptáculos de transformaciones necesarias para generar cambios” (576). Al reclamar la capacitación científica en la mujer, las periodistas cruzan las zonas de diferenciación intelectual y laboral enmarcadas dentro del contexto familiar y nacional. Sus proyectos educativos generan un espacio discursivo que apunta a la integración femenina y a la regeneración moral, social y económica de la sociedad. Desde el surgimiento de La Educación (1852), Rosa Guerra dialoga con las limitaciones o fronteras laborales impuestas por los sectores de poder masculinos en las mujeres y genera un disentimiento que cuestiona la falta de capacitación educativa femenina. ${ }^{8}$ Como estrategia discursiva, Guerra alude a los cruentos sucesos de violencia experimentados durante el mandato de Juan Manuel de Rosas (1829-1852) para ejemplificar las diversas situaciones de desesperación en las

8 La edición del periódico literario La Educación estuvo a cargo de la escritora Rosa Guerra, quien a los dos meses de la desaparición de su primer periódico, La Camelia, retorna al campo de la prensa femenina con una nueva publicación dedicada al sexo femenino. En el encabezado de este semanario Guerra aclara que el mismo "tratará de todo", premisa que se hace evidente en su primer artículo editorial el cual elabora sobre el período rosista; entre esta variedad temática se encuentran la regeneración política del país, la resurrección de la patria argentina, los exiliados y la influencia de la mujer en la política, entre otros puntos. A diferencia de La Camelia, La Educación contó con la protección del gobierno provisorio, el cual no sólo se subscribe al periódico sino que también lo adopta como material de lectura en las Escuelas de Beneficiencia. Lo cierto es que la necesidad de Guerra de usar un seudónimo, "Cecilia”, sumado al hecho de que el semanario despareció después de su sexta emisión muestra la tensión vigente en el periodismo de entonces, el cual todavía era considerado un privilegio masculino.

$\begin{array}{lllll}\text { ISSN 2154-4794 (Electrónico) } & \text { Revista Iberoamericana, Vol. LXXVII, Núms. 236-237, Julio-Diciembre 2011, 717-730 }\end{array}$ 
que la mujer argentina se transformó repentinamente en la responsable de mantener económicamente a su familia sin contar con la formación educativa que pudiera posibilitar el cumplimiento de los deberes que el momento político le imponía. ${ }^{9}$ Guerra inaugura su discusión sobre esta temática en el artículo editorial de su primer fascículo en donde brinda su testimonio sobre el período rosista y su influencia en las mujeres: "En el tiempo de la tiranía hemos experimentado la necesidad que tenemos que se nos dé una educación capaz de bastarnos a nosotras mismas, a nuestras necesidades” (24 de julio de 1852: 3). Las numerosas referencias a la reciente tiranía, todavía viva y doliente en la memoria colectiva, articulan un discurso testimonial, didáctico y correctivo que insiste en la necesidad de aprender de los errores del pasado y en la urgencia de capacitar científicamente a las jóvenes para poder asegurar su autoabastecimiento. La prensa femenina comparte el "optimismo del siglo diecisiete de imponer a través de la ciencia una educación moderna para generar el bienestar y la transformación material de la sociedad” y le brinda, a su vez, un carácter reparativo (Saldaña 3).

La incertidumbre e inestabilidad política y económica propia del siglo diecinueve demandaba un cambio de perspectiva en la vida de las mujeres argentinas quienes podían adoptar una actitud protagonista. El reclamo de la emancipación intelectual femenina por parte de las periodistas apunta precisamente a establecer la independencia económica de las jóvenes, y su participación activa y pública en el proceso de desarrollo nacional. La educación científica en la mujer posibilitaba su salida laboral y su contribución directa en los proyectos que intentaban consolidar el desarrollo económico de la nación. Debido a su característica utilitaria y remunerativa, las ciencias conformaban una avenida productiva clave para insertar a la mujer en el campo laboral.

El registro del Departamento de Educación muestra la gran necesidad que tenía el país de contratar a maestras con especialidades en diferentes ramas de la ciencia. Ante el aviso de puestos de trabajos disponibles para la inauguración de la Escuela Superior en Buenos Aires, se presentaron solamente ocho solicitudes de mujeres en comparación con la abrumadora cifra de ciento diez maestros (Anales de la Educación Común en el Estado de Buenos Aires 175). Este claro desequilibrio en la educación del pueblo argentino era consecuencia del reservar los estudios científicos en la mujer para la oligarquía, única clase social que podía costear los gastos de las escuelas privadas. Los proyectos científicos de la prensa femenina tuvieron por objetivo el ampliar las

9 Juan Manuel de Rosas dirigió el destino de Argentina como gobernador de la provincia de Buenos Aires por un período de diecisiete años (1829-1845). Durante su mandato, Rosas instituyó un régimen dictatorial que violaba las leyes de la Constitución e imponía un sistema de represión política que forzaba a sus adversarios al exilio (Lewis 43). Como estrategia de manipulación y dominio ideológica y política, Rosas frenó el desarrollo educativo del pueblo con la intención de controlar las posibilidades de resistencia hacia el sistema federalista y la posible emergencia de nuevos núcleos de formación liberal.

Revista Iberoamericana, Vol. LXXVII, Núms. 236-237, Julio-Diciembre 2011, 717-730 ISSN 0034-9631 (Impreso) 
oportunidades laborales de la mujer en un período histórico en que las perspectivas de trabajo eran escasas.

Cabe señalar que un aspecto clave del éxito en la implementación de las ciencias en el sistema educativo argentino era su complementación industrial. La literatura periodística femenina señala la propiedad de adoptar una enseñanza científica e industrial en los centros educativos públicos con el objetivo de retener a los alumnos de limitados recursos económicos y poder así alcanzar una capacitación práctica que desembocara en una especialización. En su periódico Álbum de Señoritas (1854), Juana Manso arguye que las "familias pobres se dán siempre prisa á sacar sus hijos de la escuela para hacerles aprender un oficio" (18). Ante esta situación, Manso propone la fundación de "casas de refugio ó asilo" en las cuales los "ramos industriales" conformaban una "parte forzosa de esos establecimientos” debido a su función retributiva (18). Un aspecto importante de este proyecto educativo es el impulso que daría a la industria, ya que los alumnos de ambos sexos podían participar en las clases industriales en las que se fomentaba el desarrollo de un oficio. Manso subraya que las mujeres en estos centros educativos públicos podían, por ejemplo, enfocarse en la industria textil y confeccionar la vestimenta que se destinaría al uso interno de los establecimientos y a la vez participar en la comercialización de la misma. El plan educativo de Manso apunta a reforzar la debilidad más aparente de la industrialización argentina decimonónica, la cual se encontraba en el sector textil, especialmente en el de la vestimenta (Bulmer-Thomas 145). Manso presenta un compendio de propuestas innovadoras y revolucionarias que marcan el rumbo pedagógico a seguir como respuesta al desarrollo industrial que experimentaba el país en su proceso de modernización. Recién en 1859, Domingo Faustino Sarmiento, haciendo uso de sus facultades de Jefe de Departamento de Escuelas de Buenos Aires, implanta la coeducación de los sexos, nombrando como directora de la primera Escuela Primaria de Ambos Sexos $\mathrm{N}^{\circ} 1$ a Juana Manso. ${ }^{10}$ Durante su mandato, la periodista tuvo la oportunidad de implantar sus ideales educativos ya expuestos en sus artículos editoriales de 1854.

Las periodistas argentinas insertan sus voces en los debates educativos públicos insistiendo, ya en una temprana época, en la necesidad impostergable de implantar en el espacio argentino un sistema de educación científico común y mixto con la intención de modificar significativamente la dinámica social femenina. En los imaginarios nacionales de las editoras y colaboradoras de las revistas y periódicos literarios femeninos, la educación se consideraba, como señala Michel Foucault en otro contexto, un sistema

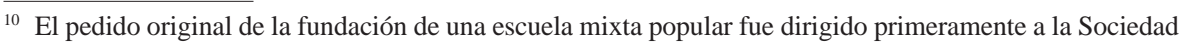
de Beneficiencia, la cual rechazó la propuesta de Manso. Este hecho forzó la intervención de Domingo Faustino Sarmiento y Bartolomé Mitre, quienes posibilitaron la instalación de la primera escuela mixta en Buenos Aires.

ISSN 0034-9631 (Impreso) 
de dominación capaz de controlar las conductas de los individuos y de someterlos a través del ejercicio de poder hacia ciertas finalidades (125). ${ }^{11}$ Su universalización y su componente científico pretendía cambiar la personificación social de las jóvenes al alejarlas del superficialismo y acercarlas hacia temáticas de mayor trascendencia. Sin lugar a dudas, esta transformación ayudaría a establecer una imagen más positiva en el exterior, específicamente en los Estados Unidos y en los países europeos en donde, a diferencia de Argentina, la enseñanza de la mujer no era "efímera ni superficial; no, [era] sumamente esmerada y científica” (La Camelia 2 mayo 1852: 1). La crítica extranjera conformaba una preocupación que se reitera en la prensa femenina a partir de 1852, con el lanzamiento del periódico La Educación. Aquí es donde se comienza a reproducir la visión extranjera de la sociedad argentina y donde se empieza a visualizar a la educación científica de la mujer como una avenida que conducía a la recreación de la imagen argentina en el exterior. Rosa Guerra ilustra la transformación que la educación científica podía generar en su carta del 7 de agosto de 1852:

Entonces se hablará en los salones como en los mas reducidos estrados, y aun en el hogar doméstico; de historia, de geografía, de música, de poesía, de pintura, de autores de literatura, de escritores de viages, de etc. etc. De este modo no se criticará tanto por el extranjero lo insulso é insignificante de nuestra sociedad reducida ha hablar únicamente de modas y de tantas vulgaridades que ocurren en el interior de la familia y que solo se deben tratar en el caso. Entonces se olvidará esa crítica mordaz que hace el alma y el elemento de nuestras tertulias y sociedades. Habiendo cosas serias y de interés de que ocuparse, no se pensará en sacar la conversación de tal, ó tal persona; de esta, ó aquella familia; sus rentas, sus economias, sus compromisos, su modo de vivir, etc. (2)

La ciencia ponía fin al materialismo y a la crítica social interna del país, mejorando de esta manera el proceder de las mujeres y su concepción en el exterior. El conocimiento científico distanciaba a las jóvenes de las preocupaciones superficiales sobre su persona y generaba un cambio de actitud radical que posibilitaba su contribución en el proceso de construcción nacional. En el contexto europeo, la educación científica había generado mujeres célebres que se distinguían en diferentes ramos de las ciencias y que habían contribuido significativamente a la sociedad de su tiempo. En el discurso periodístico femenino se brindan pruebas convincentes de que la mujer poseía la habilidad de capacitarse "en todo género de ciencias" (24 julio 1852: 2). Rosa Guerra es una de las editoras que utiliza la práctica discursiva del catalogo histórico para "documentar" la participación de la mujeres europeas en el área de las ciencias y su consecuente colaboración en el desarrollo económico y cultural de sus respectivos países (Pratt

${ }^{11}$ Con imaginario nacional me refiero a la forma en que la nación se concibe imaginariamente en un discurso (Anderson 15). Revista Iberoamericana, Vol. LXXVII, Núms. 236-237, Julio-Diciembre 2011, 717-730
ISSN 2154-4794 (Electrónico) 
17). Esta estrategia narrativa aporta aún más relevancia a los proyectos pedagógicos propuestos por la prensa femenina, ya que se concentran no solamente en ideas, sino en pruebas indiscutibles a la hora de examinar el rol de las ciencias en la educación de las mujeres decimonónicas. ${ }^{12}$

Los programas educativos de carácter científico planteados en la narrativa periodística femenina demuestran la determinación de escritoras como Juana Manso en cambiar la dinámica social, cultural, económica y política de su tiempo. Su Álbum de Señoritas crea un espacio combativo en el que enfrenta el estado letárgico de las autoridades políticas en relación a la puesta en marcha de las propuestas pedagógicas que pretendían organizar la sociedad y consolidar su desarrollo. Manso expone la tendencia del gobierno de pedir planos y recibir proyectos, solamente para ser sistemáticamente archivados (42). La inoperancia política se identifica como la causa principal de la crisis socio-educativa del país. Esta es la razón por la que Manso, con un marcado pesimismo, confiesa no tener esperanza alguna de que sus proyectos educativos llegaran a ser materializados. Sin embargo, ella no deja de anticipar y refutar las posibles objeciones económicas que su propuesta pedagógica pudiera generar y plantea la posibilidad de solventar sus “casas de refugio ó asilo” con la fundación de una lotería pública establecida por el gobierno (27). Manso parte del modelo de educación estadounidense de intervención gubernamental y demanda la participación de los líderes políticos en la organización y administración de los organismos de enseñanza tanto públicos como privados. ${ }^{13}$

Luego de dejar por sentado la misión organizativa del gobierno, esta periodista propone el reemplazo de los libros existentes en los establecimientos educativos por aquellos que contengan nociones científicas, especialmente en el campo de la geografía, geometría e historia (Álbum 42). Asimismo, Manso insiste en la necesidad de que el gobierno emita una ley institucional que instituya la metodología de enseñanza y el material cognoscitivo para poner fin a la arbitrariedad de los educadores y así poder modificar radicalmente la atmósfera educativa decimonónica. En un momento clave

${ }_{12}$ Francine Masiello resalta que la recomendación por parte de Rosa Guerra de tomar como modelo educativo el ejemplo de Europa renovaba el debate sobre civilización y barbarie (281). El conocimiento científico constituía una de las ventajas de las mujeres europeas en materia de educación, por lo que su implementación en los proyectos educativos decimonónico tenía el efecto de disminuir la distancia entre Europa y Argentina (281).

${ }_{13}$ En la cultura impresa femenina el sistema de enseñanza estadounidense se visualiza como el epítome educativo por haber logrado expandir la educación a todos los extremos del país, unificando y consolidando el progreso de la nación bajo el emblema de la enseñanza popular y mixta. La educación constituía una de las preocupaciones centrales del gobierno estadounidense materializada en la fundación de múltiples escuelas públicas destinadas a la enseñanza de ambos sexos. Las periodistas destacan en diversas ocasiones que el éxito en la implementación del sistema educativo estadounidense fue la iniciativa del Estado de intervenir en la organización e implementación de la enseñanza del pueblo, situación que se esperaba trasladar al espacio argentino.

Revista Iberoamericana, Vol. LXXVII, Núms. 236-237, Julio-Diciembre 2011, 717-730
ISSN 2154-4794 (Electrónico) 
del proceso educativo argentino, Álbum de Señoritas traza un modelo de enseñanza revolucionario por el cual no sólo se intenta popularizar el conocimiento científico, sino que también se propone remarcar la responsabilidad del gobierno en la implementación de las reformas pedagógicas que trazaran el destino progresista de la nación.

En suma, la prensa femenina decimonónica funcionó como un órgano de encuentro y contención indispensable para varias escritoras y lectoras quienes se proponían combatir las doctrinas de secularización social vigentes en el siglo diecinueve. Por medio de la emisión de periódicos y revistas literarias se logra crear un forum diseñado exclusivamente para que la mujer argentina pudiera acceder y participar en la discusión de diversas temáticas ya expuestas a un nivel público. De esta manera, las voces femeninas socialmente marginadas llegan a sobrepasar los estrechos límites de acción que les imponía una sociedad cromáticamente jerarquizada y colocan en primera plana su misión de reivindicar la condición de la mujer argentina y ampliar la noción de lo que se consideraba como concomitante a su género sexual. Las periodistas invaden la prensa bonaerense concebida como un espacio discursivo netamente masculino e introducen la perspectiva femenina en los debates nacionalistas. Sus discursos presentan una visión alternativa ante la normativa educativa de la época que limitaba la educación científica de la mujer. Se subrayan las deficiencias intelectuales y económicas de las políticas de educación vigentes y se propone la unificación de las prácticas pedagógicas bajo un sistema educativo coherente y práctico centrado en las ciencias. La inclusión de la industria dentro de sus proyectos educativos apunta a reforzar la función retributiva de las ciencias y a modificar la dinámica social al insertar a la mujer en el campo laboral decimonónico. La educación científica se inserta en los proyectos pedagógicos de la prensa femenina con la intención de transformar el accionar femenino y traspasar las zonas de diferenciación social, intelectual y laboral enmarcadas dentro del contexto familiar y nacional.

La ensayística presente en los periódicos y revistas literarias femeninas demuestran la manera en que las periodistas se embarcan en la tarea de teorizar sobre lo femenino, es decir, emprender el proceso de contemplación de la problemática de la mujer en el contexto argentino. En la época, el concepto de teorizar tenía como significado el "tratar o discurrir un asunto”; actividad que constituyó el eje central del discurso periodístico femenino en relación a la condición social, cultural y educativa de la mujer (Moliner 1292). Las editoras y colaboradoras de la prensa femenina examinan la administración del saber entendiendo su funcionamiento como "técnicas o tácticas de dominación" que frenaban la participación activa y directa de la mujer en cuestiones nacionales (Foucault, Microfísica 156); en cada punto del cuerpo social existen relaciones de poder que operan a través del saber (125). Si pensamos en la cultura impresa femenina, se puede visualizar cómo las periodistas presentan un amplio compendio de proyectos destinados a descentralizar las oportunidades científicas en el campo educativo con el

\footnotetext{
ISSN 2154-4794 (Electrónico)
ISSN 0034-9631 (Impreso)
} 
objetivo de insertarse en las redes de poder decimonónico. La ciencia se ubica en el centro de sus proyectos educativos, ya que se concibe como la única herramienta válida para alcanzar un tipo de educación certera, sólida y completa que pudiera materializar la reconfiguración de la mujer en el plano nacional. El conocimiento científico como un cuerpo de doctrinas metódicamente formado y ordenado que sólo admite "principios, consecuencias y hechos rigurosamente demostrables" se convierte en una avenida productiva por la cual se pretende revertir la marginalidad femenina (Diccionario de la lengua española 281). En los imaginarios nacionales de las periodistas argentinas, la educación científica se concibe como la fuente generadora de la estabilidad económica y moral de la familia. Sobresale la figura de la madre que, al inculcar el saber científico en sus hijos forja, ciudadanos responsables y capaces de conducir el destino de la nación. Las periodistas resaltan los diferentes canales de socialización por los cuales la mujer científica participa activamente en el proceso de organización y consolidación nacional. El vasto compendio de propuestas científicas presente en los periódicos y revistas femeninas conforman el germen de las doctrinas pedagógicas que llegaron a solidificar el programa de convergencia educativo argentino. Sus ensayos revelan una postura crucial para entender la dinámica de los diálogos nacionalistas decimonónicos.

\section{Bibliografía}

Adorno, Theodor. “The Essay as Form.” New German Critique 32 (1984): 151-71.

Anales de la educación común en el estado de Buenos Ayres, publicación mensual bajo los auspicios del Departamento de Escuelas. Buenos Aires: Imprenta del Nacional, 1861.

Anderson, Benedict. Imagined Communities. Reflections on the Origin and Spread of Nationalism. Nueva York: Verso, 2002.

Auza, Nestor Tomás. Periodismo y feminismo en la Argentina 1830-1930. Buenos Aires: Emecé, 1988.

Babini, José. La ciencia en la Argentina. Buenos Aires: Editorial Universitaria de Buenos Aires, 1963.

Bourdieu, Pierre. Distinction: A Social Critique of the Judgement of Taste. Cambridge, MA: Harvard UP, 1994.

Bulmer-Thomas, Victor. The Economic History of Latin America Since Independence. Cambridge: Cambridge UP, 1994.

Diccionario de autoridades. Madrid: Gredos, 1964.

Diccionario de la lengua española. Madrid: Talleres Calpe, 1925.

Foucault, Michel. Microfísica del poder. Madrid: Gráficas García Rico, 1992. Power/Knowledge: Selected Interviews and Other Writings. Colin Gordon, ed. Nueva York: Pantheon Books, 1980.

\footnotetext{
ISSN 0034-9631 (Impreso)
} 
Good, Graham. The Observing Self: Rediscovering the Essay. Londres: Routledge, 1988.

Guerra, Rosa. La Educación. Periódico religioso, poético y literario, dedicado a la honorable Sociedad de Beneficiencia y al bello sexo argentino. Buenos Aires: n.p., 1852.

La Aljaba. Dedicada al bello sexo Argentino. Buenos Aires: Imprenta del Estado, 1830.

La Camelia. Buenos Aires: Imprenta Republicana, 1852.

La Moda, gacetín semanal, de música, de poesía, de literatura, de costumbres. Buenos Aires: n.p., 1837.

La Ondina del Plata. Buenos Aires: n.p., 1875.

Lewis, Daniel K. The History of Argentina. Nueva York: Palgrave, 2001.

López, Jeannette. La mujer y la historia argentina. Buenos Aires: Plus Ultra, 1991.

Lukács, Georg. "On the Nature and Form of the Essay.” Soul and Form. Londres: Merlín P, 1974. 1-18.

Manso de Norohna, Juana. Álbum de Señoritas. Buenos Aires: Imprenta Americana, 1852.

Marco, Miguel Ángel de. Historia del periodismo argentino. Desde los orígenes hasta el Centenario de Mayo. Buenos Aires: Editorial de la Universidad Católica Argentina, 2006.

Masiello, Francine. "Ángeles en el hogar argentino. El debate femenino sobre la vida doméstica, la educación y la literatura en el siglo XIX”. Anuario IEHS 4 (1989): 265-91.

Meléndez, Mariselle. "Obreras del pensamiento y educadoras de la nación: el sujeto femenino en la ensayística femenina decimonónica de transición”. Revista Iberoamericana XLIV/182-183 (1998): 573-86.

Meyer, Doris. "Introduction. The Spanish American Essay. A Female Perspective." Reinterpreting the Spanish Essay. Women Writers of the $19^{\text {th }}$ and $20^{\text {th }}$ Centuries. Doris Meyer, ed. Austin: U of Texas P, 1995. 1-9

Moliner, María. Diccionario de uso del español. Madrid: Gredos, 1967.

Nussbaum, Felicity, ed. Introducción. The Global Eighteenth Century. Baltimore: Johns Hopkins UP, 2003.

Pratt, Mary Louise. “'Don’t Interrupt Me’ The Gender Essay as Conversation and Counteracanon.” Reinterpreting the Spanish American Essay. Austin: U of Texas P, 1995. 10-26.

Saldaña, Juan José. Science in Latin America. A History. Austin: U of Texas P, 2006.

Sosa de Newton, Lily. Diccionario biográfico de mujeres argentinas. Buenos Aires: Plus Ultra, 1980.

Verdevoye, Paul. Costumbres y costumbrismo en la prensa argentina. Desde 1810 hasta 1834. Buenos Aires: Academia Argentina de Letras, 1994.

ISSN 0034-9631 (Impreso) 